University of Nebraska - Lincoln

DigitalCommons@University of Nebraska - Lincoln

Faculty Publications from Nebraska Center for Research on Children, Youth, Families, and Schools
Children, Youth, Families \& Schools, Nebraska Center for Research on

2021

\title{
Using photovoice to understand and amplify youth voices to prevent sexual and relationship violence
}

\author{
Victoria Banyard \\ Katie Edwards \\ Ramona Herrington \\ Skyler Hopfauf \\ Briana Simon
}

See next page for additional authors

Follow this and additional works at: https://digitalcommons.unl.edu/cyfsfacpub

Part of the Bilingual, Multilingual, and Multicultural Education Commons, Child Psychology Commons, Counseling Psychology Commons, Developmental Psychology Commons, Early Childhood Education Commons, Educational Psychology Commons, Family, Life Course, and Society Commons, and the Other Social and Behavioral Sciences Commons

This Article is brought to you for free and open access by the Children, Youth, Families \& Schools, Nebraska Center for Research on at DigitalCommons@University of Nebraska - Lincoln. It has been accepted for inclusion in Faculty Publications from Nebraska Center for Research on Children, Youth, Families, and Schools by an authorized administrator of DigitalCommons@University of Nebraska - Lincoln. 
Authors

Victoria Banyard, Katie Edwards, Ramona Herrington, Skyler Hopfauf, Briana Simon, and Linda Shroll 


\title{
Using photovoice to understand and amplify youth voices to prevent sexual and relationship violence
}

\author{
Victoria Banyard, ${ }^{1}$ Katie Edwards, ${ }^{2}$ Ramona Herrington, ${ }^{2}$ \\ Skyler Hopfauf, ${ }^{2}$ Briana Simon, ${ }^{2}$ Linda Shroll ${ }^{3}$
}

1 School of Social Work, Center on Violence Against Women and Children, Rutgers University, New Brunswick, New Jersey, USA

2 Center for Research on Children, Youth, Families, and Schools, University of Nebraska-Lincoln, Lincoln, Nebraska, USA

3 Working Against Violence, Inc, Rapid City, South Dakota, USA

Correspondence - Victoria Banyard, School of Social Work, Center on Violence Against Women and Children, Rutgers University, 123 Church St., New Brunswick, NJ 08901, USA. Email: Victoria.banyard@rutgers.edu

ORCID

Victoria Banyard http://orcid.org/0000-0002-9645-5055

Katie Edwards https://orcid.org/0000-0003-1888-7386

\begin{abstract}
Aims: Efforts to improve prevention of sexual and relationship violence (SRV) among adolescents call for more centering of youth voices, experiences, and skills to design prevention programs that incorporate youth engagement rather than those that are designed by adults for youth. Amplifying the voices of historically marginalized youth are especially needed. Photovoice (PV) is a participatory action method that can empower youth and generate prevention knowledge.

Methods: The current project used PV to engage youth in late middle and early high school to discuss how they could work to prevent SRV in their community. A
\end{abstract}

Published as: Banyard V., Edwards K., Herrington R., Hopfauf S., Simon B., Shroll L. Using photovoice to understand and amplify youth voices to prevent sexual and relationship violence. J. Community Psychol. 2021, 21pp. DOI: 10.1002/jcop.22495

Copyright (C) 2020 Wiley Periodicals LLC. Used by permission.

Submitted 10 July 2020; revised 1 December 2020; accepted 2 December 2020; published 17 December 2020. 
convenience sample of nine youth (predominately Native American) participated over seven sessions.

Results: A key theme they generated is that SRV prevention needs to be viewed as relational. Participants described the complexity of prevention, including how youth need social support to thrive and prevent SRV and that asking for help can be challenging. Results also highlighted that youth can provide help and support, but it is not always welcome in addition to underscoring that youth are resilient and can be prevention leaders.

Conclusion: Innovations in SRV prevention, especially for older adolescents, should work to engage youth as prevention partners. Participatory research methods like photovoice can be an important part of that process.

Keywords: adolescence, bystanders, photovoice, prevention, relationship violence, sexual violence, youth voice

\section{Introduction}

Research documents the emergence of peer sexual and relationship violence (SRV) as a significant problem during adolescence, with negative impacts on mental and physical health, as well as developmental tasks like school performance (Edwards, 2018; Exner-Cortens et al., 2013). Definitions of SRV include a continuation of behaviors from sexual harassment to unwanted sexual contact and rape and physical and psychological abuse by a dating partner. Recent data from the Centers for Disease Control and Prevention (CDC) showed that 1 in 10 high school students reported a sexual assault in the past year and that 1 in 8 high school students reported physical dating violence in the past year; rates of SRV are even higher among Native American youth (Prevention, 2020).

Along these lines, recent efforts to improve prevention of SRV call for more centering of youth voices, experiences, and skills to design prevention with youth engagement rather than by adults for youth (Edwards et al., 2016; Sprague Martinez et al., 2018), and this is especially critical for marginalized youth, such as Native youth, who are rarely included in such conversations. Participatory action research (PAR) methods may be helpful in this regard since they aim to empower participants, while also generating knowledge to promote change, or in this case, to build more effective prevention innovations (MacEntee, 2020; Yuan et al., 2016). Methods that help youth tell their own stories using visual materials such as photos and collages have also been effective 
with youth and are also highly relevant ways of expressing lived experiences for Native youth (Hodge et al., 2002; Lightfoot et al., 2019; Mackworth-Young et al., 2020). The current project used photovoice (PV) to engage a sample of largely Native youth in late middle and early high school to discuss how they could work to prevent SRV in their community. It builds on broader PV work with youth who identify SRV as critical issues for young people in communities locally and globally (Daniels, 2018; Irby et al., 2018; Mitchell et al., 2006).

\subsection{The need for youth voices in SRV prevention}

Empowerment is about increasing access to power so that individuals and groups can take action to improve their lives (Cattaneo \& Chapman, 2010; Gutierrez, 1995), and this is especially critical for youth who are historically and presently marginalized such as Native youth. As a process, empowerment involves setting power-based goals, taking actions toward those goals, and reflecting on the impact of those actions (Cattaneo \& Chapman, 2010). Recent work in SRV prevention for youth discusses how prevention is often created by adults for youth with very little input from youth themselves (Edwards et al., 2016; Tilbury et al., 2019). Researchers and prevention practitioners postulate that this may be one reason for some of the lack of success that the field experiences in trying to reduce perpetration and victimization among adolescents. The CDC and Prevention's STOP Sexual Violence technical package (Basile et al., 2016) lists empowerment, especially of girls and women, as a key foundation for effective SRV prevention. Youth-centered studies of SRV are growing in number, usually around specific forms of violence or specific aspects of prevention.

SRV prevention research has expanded in the past decade, with a growing number of programs showing promising evidence of effectiveness for middle and high-school students as well as young adults in college (Edwards et al., 2019; Foshee et al., 2005; Moynihan et al., 2015; Niolon et al., 2019). Programs that are most effective in reducing SRV are those that map hotspots and improve response protocols, programs that train youth to be positive bystanders to intervene in situations of SRV and shift social norms to be intolerant of SRV, programs that teach girls empowerment self-defense skills, and programs that engage parents and teachers in reinforcing prevention program messages (Coker et al., 
2019; Miller et al., 2012; Orchowski et al., 2018; Rizzo et al., 2020; Testa et al., 2010). More recent work that does more to examine group differences, finds that programs do not work equally well for all participants (Moynihan et al., 2015; Waterman, 2020). A study of the Green Dot high school curriculum found that it did not show positive effects for sexual minority youth (Coker et al., under review). A study of college students from historically marginalized racial/ethnic and sexual and gender minority communities indicated that young adults found SRV prevention efforts very limited to individual levels of action rather than institutional change and needed more grounding in principles of social justice and community action (McMahon et al., 2020). This study argues for the need for more participant voices in prevention design.

Given the current state of SRV prevention challenges, research is needed that better centers the experiences of a range of youth and young adults. What might we be missing in how we are framing SRV prevention that may not be currently resonating with them? This may be especially important in communities with a large presence of Native youth for which we know very little about effective SRV prevention (Edwards et al., in press; Edwards et al., under review). PAR methods are those that involve participants as decision-makers who collaborate with researchers on all parts of a project. They are useful for involving and amplifying the voices of participants who have historically been left out of research studies, and provide a vehicle for participants to use research to understand and solve community problems (Yuan et al., 2016). Researchers and participants create knowledge together (Jennings \& Lowe, 2013). PAR may be one way to begin to understand prevention programs through the eyes of the youth audiences that they are intended for. Further, PAR can also help to build empowerment because participatory methods encourage youth to define the goals of a project, use the project to create action for community change, and reflect on social problem and social change impacts.

\subsection{PV as a method to center youth SRV experiences}

\subsubsection{Defining $P V$}

PV is a PAR method that engages underrepresented and marginalized groups in exploration and critical analysis of a problem their community 
faces (Strack et al., 2004; Suprapto et al., 2020; Wang \& Burris, 1997). Theoretically, it is grounded in feminist and critical consciousness theories that emphasize the need for collaboration with participants in generating knowledge that contributes to social change and methods that encourage dialogue about issues that community members determine are central to their lived experience (Mitchell, 2018; Wang \& Burris, 1997; Wang et al., 1998; Wang, 1999). Photographs become a tool for narrative storytelling. Participants, usually from groups that do not hold power, whose voices are unheard, and who are often treated as passive objects of study, instead share power with researchers in defining the topics for photographs and discussion. They are co-researchers who are involved in creating narratives to describe photo themes that reflect participants' own standpoints and experiences rather than just the interpretations of researchers.

This is especially relevant to the current study given that storytelling is a long-honored way of teaching life lessons among Native communities. Native Americans have experienced numerous historical traumas (e.g., forced placement in boarding schools, assimilation, land loss, genocide, forced sterilization of Native women, poverty). These historical traumas have resulted in loss of culture, history, and language (Kingston, 2015), all of which have resulted in a number of deleterious health consequences (Heart, 2003; Rutman et al., 2008). Furthermore, violence, including SRV, was rare among Native Americans before colonialization. SRV is a tool that has been used by colonizers to oppress and an intersectional approach to understanding SRV is needed (Clark, 2012; Gill, 2018; Harris \& Linder, 2017; Resistance \& Incite!, 2003; Richie, 2015). Despite these traumas and inequities, Native communities remain resilient, owing to the presence of protective factors that prevent violence and buffer adversity (e.g., cultural connectedness, positive social norms; see Henson et al., 2017). As a form of PAR, PV may be a particularly important research method for historically oppressed communities such as Native Americans since researchers have historically been part of the systems of racial trauma they have experienced (Mitchell, 2018) and since participatory methods like PV can deepen connection and sense of collective power among participants (Foster-Fishman et al., 2005).

Participants use photographs as a springboard for analyzing the causes of the problem, reflecting on personal meanings of the problem, envisioning solutions, and sharing those solutions with the broader 
community (Lightfoot et al., 2019; Woods-Jaeger et al., 2013). In addition, at the end of PV, participants organize a community forum to display the photographs and themes from the discussion. Community leaders are invited to the forum, which provides them with an opportunity to hear about the experiences and ideas for action from groups of community members whose voices are less often heard. These forums also serve as a mechanism for the diffusion of new ideas as described by Diffusion of Innovation Theory, a foundation of many SRV prevention efforts (Rogers, 2002).

\subsubsection{PV and youth}

PV projects with youth have helped health educators better include the perspectives of indigenous youth in the design of prevention (Jennings \& Lowe, 2013; Markus, 2012), medical professionals understand the lives and challenges of Latinx youth in their community, helped African-American youth explore HIV vulnerability, and examined youth perceptions of community violence (Chonody et al., 2013; Irby et al., 2018; Lightfoot et al., 2019; Woods-Jaeger et al., 2013). PV has been used as a tool for adapting prevention strategies (Kubicek et al., 2012). Indeed, the method aligns well with the process of empowerment (Cattaneo \& Chapman, 2010) since the focus is on participants choosing what is discussed and shaping an interactive community forum to make their perspectives, needs, and ideas for action known to community leaders.

\subsubsection{PV and SRV}

More specific to SRV, the method has been used to elevate the voices of survivors and help promote recovery, more of a tertiary level of prevention (Frohmann, 2005). These projects helped to illustrate key problems of concern to survivors who participated, created an environment for self-care and social support, and made connections to resources (Christensen, 2019).

There has been less specific work using PV within specific SRV prevention spaces among youth. However, the large body of PV projects with youth to understand broader issues related their health and development often describes the role of SRV and other forms of violence in the lives of youth (Irby et al., 2018; Mitchell et al., 2006). These projects 
also illuminate the resilience and strengths of young people in the face of these challenges (Bayer et al., 2014; Khumalo et al., 2018). In one key study youth used PV to document sexual violence by peers, the isolation and trauma victims experienced and the importance of social support (Ngidi \& Moletsane, 2019).

The purpose of the current study was to extend previous research to examine how youth think about SRV prevention and their role in such prevention using a PV methodology. Prevention is a science and important research has documented key risk and protective factors that inform the content of prevention strategies (Vagi et al., 2013). We also know that an intersectional perspective on prevention questions has been underutilized (Collins, 2017). Researchers, using methods that more fully engage youth in conversations about how they think about SRV can help preventionists improve programs to be more culturally responsive to youths' experiences and build on aspects of adolescents' lives that really matter to them. PV provides a structured PAR approach that creates scientist-youth collaborations to amplify youths' voices in conversations about prevention using structured and trustworthy research methods. Youth who were part of a community that was actively implementing a SRV prevention program were asked to speak about their views of the problem of SRV and how youth can play a role in preventing it. PV took place in the fourth year of the project, after two years of prevention implementation in the community. The goal was to engage youth who were aware of SRV prevention in conversations about how youth were able to play roles in prevention and what aspects of youth experiences the project might need to keep attending to. PV was also an opportunity to bring the youth-led prevention work more to the attention of adults and community leaders, to amplify youth views on how the community should continue to think about SRV prevention.

\section{Methods}

\subsection{Participants}

Nine youth in grades 8 and 9 participated in five PV discussions of photo assignments and two overall thematic discussions and community forum planning sessions. Youth were recruited by word of mouth in the 
community including emails sent out by project contacts within schools and from contacts (flyers, emails, social media posts) with parents/ guardians and youth connected to a larger prevention project that enrolled students in grades 7-10 in a longitudinal study of the impact of a youth-led SRV prevention initiative in a small city in the Great Plains region of the United States. The city in which the project took place has a large presence of Native Americans and rates of poverty above the national average.Moreover, the city in which the project took place is near two large Indian Reservations that are characterized by some of the highest rates of poverty in the United States.

The larger project involved collaboration among community agencies, the school district, and university researchers. At the time of PV recruitment, the prevention initiative had been in place for three years and thus the community was familiar with the overall project name and with project staff. Importantly, the PV facilitators (described below) were wellknown community members and leaders and they assisted with recruitment. Nine youth completed a demographic questionnaire. Six of these youth were Native American and three were White; six were girls and two were boys (one chose not to answer the gender question); and one indicated they were of a sexual minority group (based on a question about sexual orientation). Participants represented four middle and two different high schools in the community. All but one of the youth participated in SRV prevention activities that were part of a larger funded project to evaluate a youth-led SRV prevention program (these included overnight camps to train youth as prevention leaders, out of school meetings during which youth met to discuss and teach other youth about various SRV primary prevention strategies including social norms campaigns; see Edwards et al, in press-b and Waterman et al., under review, for more details on programming). All youth were part of a community where community agencies and the school district partnered to raise SRV awareness through action events (e.g., painted murals in downtown showcasing prevention messages). Many of the youth knew each other from school or from project prevention activities but not all youth knew each other.

\subsection{Procedures}

Participants met weekly to share and discuss photographs and plan the next photo assignments over a course of five weeks. Each session began 
with trust building check-ins about how youth were doing (current challenges and successes and interests) and youth were served food, an aspect of community building. As the sessions continued, discussions and questions youth posed to themselves and each other became very rich in content as they opened up to each other about the photos they chose. They became a group that actively supported one another, and adult facilitators noted growth in respect for each other within the group and a willingness to challenge viewpoints and form solutions.

During the 5-week period, the group was unable to meet for 1 week due to inclement weather and therefore held two sessions the following week to make up the missed session. A wrap-up discussion to plan the first community forum served as the sixth meeting. Youth $(\mathrm{N}=5$ due to scheduling conflicts) from the project were able to come together for a second reflection meeting three and a half months later to revisit key themes from the project and to reflect on community diffusion and impacts, a form of member checking. Youth led the creation of each of the specific photo assignments for each meeting. This gave us a chance to learn from youth how they think about their role in prevention, what key components of prevention are, where prevention happens, and how prevention is connected to different spaces youth inhabit (peer groups, family, schools, community).

The facilitators of PV, who are coauthors on this paper, were a Native American grandmother and activist as well as the director of a local domestic and sexual violence crisis center. Both of these adults are well known and visible to youth and families in the community, which helped build a foundation of trust in the project. Eight of the PV participants had worked with the adult facilitators in prevention training and activities related to the larger prevention project. Facilitators were trained by a consultant on the project who is an expert in training and using PV.

We followed PV procedures as described in previous work (Sidibe et al., 2018). The first session provided an introduction to the project, as well as instructions about the use of digital cameras and ground rules for photo taking and group discussions and a review of ethical issues related to photography and PV. At each session, participants shared at least one photo they took related to the assignment. The group discussed it following the outline "SHOWED" often described in the literature (Lightfoot et al., 2019). This involved sharing what youth saw in each photo (with the photographer sharing first), how they felt it related to their 
and other youths' lives, why things are this way-a more critical analysis of the problem or solution, and how they can educate others and create change about the issues they see represented in the photos. Adult facilitators helped to promote the discussion in each session by encouraging all participants to share their point of view about each photograph (Foster-Fishman et al., 2010). Adult facilitators focused more on drawing out youths' perspectives rather than offering their own but they would often summarize key points or themes and check in with youth that these summaries accurately reflected what youth were saying. In this way youth were involved each week in data generation but also data analysis as they thought about themes from the discussion (Foster-Fishman et al., 2010). In each session all youth who had a photo to share had the opportunity to present and have their photo discussed. The group chose photo assignments that reflected youth perspectives about sub-issues related to SRV prevention and were arrived at by consensus among youth each week: peer pressure; social support; what healthy and unhealthy relationships look like (including friendship); and how to be a positive bystander. During the sixth session, participants came together to choose the photos that would be in the community exhibit and to discuss key themes that organized those photos (similar to the identifying themes and recommendations activities as described by Foster-Fishman et al., 2010). A seventh reflection meeting was added several months later to continue the process of member checking with youth. This meeting occurred after six community showings of the PV exhibit had taken place and after researchers had done more data analysis. Participants reflected on what they saw as the impact of the PV project on themselves and their community. All sessions were audio-recorded with parental consent and youth assent and transcribed verbatim for analysis (with identifying information removed). The project was implemented under the approval of the Institutional Review Boards of participating universities.

\subsection{Data analysis}

Data included verbatim transcripts of PV meetings and photos submitted by youth during those meetings. Consistent with previous PV projects, data analysis was iterative for this project. First, during the PV project, adult facilitators began and ended each session by asking youth to summarize key themes and ideas from the previous and current sessions 
to involve youth in data analysis and theme generation. These themes were discussed with the research team (the two university researchers overseeing the project who themselves were trained in PV method along with the facilitators of the youth sessions and the two project research coordinators) on a weekly basis while PV was underway. At the end of the project the research team, in consultation with adult facilitators, read through verbatim transcripts, took notes on impressions (staying as close to the youths' own words as possible), and developed a series of codes related to themes that youth identified in their discussions. Researchers then created higher-order themes and illustrative quotes from these codes that were discussed with youth in session 6 . Member checking of these broader themes and conclusions was done with youth ( $\mathrm{N}=5$ of the PV participants) at a seventh reflection session several months after the first community display of the project. These methods were drawn from research on PV and guidelines for thematic analyses (Lightfoot et al., 2019; Vaismoradi et al., 2013).

\section{Results}

The goal of the project, as it was described to participants, was understanding how youth see SRV prevention and their role in prevention. While the broader project that PV was embedded in focused on primary prevention, the PV project simply used the term "prevention" and allowed youth to explore what that meant to them and the results suggest that overall youth used the project to more broadly explore SRV as it shows up in their lives. Youth described issues that connect clearly to primary prevention but also discussed elements of secondary prevention and what might be considered tertiary prevention (harm reduction/social support responses when trying to help victims who are in violent or unhealthy relationships). Below we describe the key themes that emerged from the five SHOWED discussion sessions and the two reflection sessions. We have worked to organize them around different elements of prevention as the field defines it to put youth perspectives and prevention frameworks in conversation. Due to space constraints, we are only able to share three of the photos but describe several others (youth were asked to choose this smaller subset). The final community exhibits included 13 photos and quotes chosen by youth. Researchers 
and youth participants worked together to choose photos that would represent the project.

\subsection{Key themes}

The overarching theme from the project was that SRV prevention must be seen as relational as all of the themes that emerged from photos and discussions focused on aspects of connections between individuals and peers, family, community including factors like social support, peer pressure, and social norms. Youth seem to think about SRV prevention in terms of relationships. The research team inferred this from the photo discussion transcripts and then confirmed this link in discussions and member checking with youth about the themes of the project. Youth discussed how SRV happens among peers. While we as researchers note that instances of SRV can occur outside of peer relationships (including family violence), the youth in the current project mainly chose to focus on peer relationships in their discussions. Youth discussed features of healthy and unhealthy friendships and dating relationships as they used the PV project to explore what SRV looked like and how it contrasted with healthy relationships. The themes that emerged cut across primary, secondary, and tertiary levels of prevention and suggests that youth may see these levels as interconnected (Brush \& Miller, 2019). The results below are organized around broad themes that were member checked with youth. Under each, researchers separated out those ideas that inform primary/secondary prevention efforts from those focused more on survivor support once SRV has occurred.

\subsubsection{How SRV appears in youths' lives}

Over the course of the project, youth discussed a variety of topics that were cued by the overall frame of SRV prevention that was given for the project. The range of these discussions that were provoked by this frame provides a window into how SRV appears in their lives and the range of questions that are connected to its prevention. For example, youth frequently made connections across prevention topics in their photos and discussions including drug use, bullying, and healthy friendships (not just dating or intimate relationships). Youth grappled with what unhealthy relationships look like, "Your boyfriend or girlfriend or 
whatever could be like this 'do this.' 'If you love me, like, take these if you love me, drink this if you love me, and that's just not like a good relationship. Even in the first place with the 'take this' or whatever, but the 'if you love me' is like... Yeah, and if you don't watch it, that could get really toxic really fast and that's just not a good relationship to be in." Youth raised points that crossed levels of prevention (primary, secondary, and tertiary). It should be noted that youth did not usually specifically or directly link their comments to the word "prevention" in their discussions (and they did not use terms like primary prevention). However, the fact that they raised points related to themes below in response to an assignment about prevention, and in the context of discussions where the adult facilitators often brought up the issue of prevention directly, suggests that youth were making these connections to prevention, a point that was affirmed in member-checking discussions.

\section{Primary and secondary prevention views of SDV}

For example, youth seem to grapple with issues like trust and also with agency related to how to know if a relationship is healthy or not. This reflects both primary prevention (awareness of what an unhealthy relationship is) and more of a secondary level of prevention related to identifying risk factors that emerge in a relationship. One participant said, "I feel like it'd be a bad relationship because you shouldn't be with somebody that doesn't trust you or vice versa, that you don't trust. I feel like you shouldn't be with somebody like that because many things could happen that go bad."

\section{Tertiary support for victims}

Although perpetrators are always responsible for all acts of SRV, youth in this study, along with Native youth in other research (Edwards et al., under review; Siller et al., under review), believe that an important part of fostering healthy relationships is helping youth, especially girls, to recognize situations of SRV, assert their needs in those situations, and recognize that they are worth living lives free of SRV. This aligns more with secondary prevention for at-risk groups as well as a strengthsbased harm reduction and resistance approach described also in work by Senn et al. (2015) that recognizes that until perpetrators are stopped, we need to support those who are at risk for harm to keep them as safe as possible and support their well-being while broader social change 
to end violence is enacted. Youth seemed to demonstrate that conversations provoked by the prompts "sexual violence prevention" need to attend both to primary and secondary prevention (keeping SRV from happening in the first place) and supporting people experiencing harm (Orchowski et al., 2018). Youth clearly recognized the harm caused by SRV. These perspectives should be acknowledged and honored as they also align with secondary prevention empowerment-based programs for girls that demonstrate reductions in SRV, including Native girls (Edwards et al., under review; Siller et al., under review).

A participant, who took a photo of a broken lock, described consequences of SRV and stated, "When you are in an unhealthy relationship you sometimes feel chained or trapped." Youth also noted that sometimes it can be hard to see whether a relationship is healthy or not, "I think it's because you can't always see everything clearly. You can't always see what's going on around you, if you're in a bad situation or not. Sometimes you can't always recognize it yourself, so you have other people around you to help support you. Sometimes they can make you realize what's going on." In these ways, youth explored SRV as aspects of peer relationships.

\section{The importance of relationships beyond peers}

Youth also included consideration of their relationships with family members as a topic to be considered when understanding SRV (including how families had been affected across generations by trauma, including sexual violence). One participant noted, "Usually when someone's in a bad relationship, it's not always but most of the time, it's because they may be around parents that also have the same relationship or they never had anyone that actually love and care for them. So they don't know any different. They think that that's normal or usually about relationships they can start off good and then as time goes on it can get worse."

Participants also went far beyond simply making a connection between bad relationships as a feature of SRV. They discussed how the fundamental ways they think about themselves as individuals are connected to the group (including peers and family) and that therefore our prevention solutions need to be about centering connections also. Youth discussed the complexities of these relational spaces as we will describe in more detail. They were also clear, however, that youth are eager and 
skilled navigators, who hold together the challenges and strengths in relationships and how an appreciation of these need to be centered in prevention work. Overall, youth discussed each of these themes separately, making connections more explicitly to prevention in member-checking and debriefing sessions.

\subsubsection{Relationships are complicated}

The youth spent time grappling with the ways that any one relationship does not neatly fall into a binary of healthy or unhealthy and that even the desire for connection and social support is in tension with motivation for autonomy and independence. One key subtheme is that relationships, while central to how youth think about SRV prevention, include an interplay of challenges and rewards. Indeed, all aspects of relationships that youth talked about had two sides and grappling with these complexities seemed part of what youth were saying prevention programs need to help them do. Below we describe several aspects of this tension as participants described it in their photos and discussion and as it related more to primary and secondary prevention as well as more tertiary victim support.

\section{Peer pressure and social norms: Relationship complexity in primary prevention}

The first is the tension between peer pressure, which has negative effects in their lives, and yet also the positive "peer influence" that can help them make good choices. One participant described it this way:

A lot of times, teens are pressured to do drugs and alcohol, and it's usually from their friends, from the people who are closest to them. And that's not a healthy relationship if your friend is pressuring you to do things you don't like.

Another stated: "They just want to fit in and be part of the social norm. They don't want to be the weird one, they don't want to be the outcast." This negativity exists side by side with positive influence, as two youth described. One explained, "Because pressure is something bad, and influence is something good. Influence is doing something good, pressure is when they want you to do something bad." Another said: "So 
like if you're procrastinating someone could good peer pressure you into doing what you're supposed to do, instead of peer pressuring into what you're not supposed to do."

An aspect of this is navigating how to decide when to go along with the group and when to make your own individual choices. One youth put it this way:

Because they feel the need to fit in. For example, everybody is like being a vsco girl, like carrying around hydroflasks and like, well you're not a vsco girl if you don't have a hydro flask. And like, you don't need to be a vsco girl anyways, you can just be yourself. You don't need to be defined as a vsco girl...I get that it might make you feel better, like you're part of the social norm, but you don't need to...you don't need a hydroflask to be a vsco girl.

Participants talked about many different aspects of positive relationships, including the importance of trust and respect, open communication, no judgement, working out differences, and setting your own boundaries. Youth highlighted the value of having healthy connections to others. They were also clear that their own freedom and independence also needed to be valued:

If someone's constantly relying on someone for support ... and in any situation, then they won't be able to handle that on their own...They could become ... like if you just depend on some people too much you could become codependent. You could just have those habits for a long time.

Another participant stated:

If something happens to someone and they feel like they want to resolve and do it on their own, that's what a lot of times the problem is. I want to try to do things on my own. And I don't want to admit I need support from other people.

In one of the follow-up discussion sessions, another youth said, "we all want to grow up but also have that support." One participant took a 
photo of their car speedometer as an expression of the agency and freedom they were gaining as they got older but how that independence also carried responsibility: “...big freedom, but then you also have to remember your boundaries, like the rules of the road and stuff like that and trust that, that we can keep that responsibility but still be able to use it to our advantage." Another participant also noted: "If you make a bad decision, you're going to have the consequences. Nobody else can have those consequences for you."

Participants were also clear that setting personal boundaries were an important part of healthy connections to others: "I don't want random people thinking they can just come up and give me a hug any time if I don't know them." Another stated: "Because they don't want people to ... think that they're weak ... or sometimes it's just how you were raised. You have to act tough all the time. Yeah. And stick up for yourself."

\section{Help-seeking and SRV response: Relationship complexity and survivor support}

This tension between making your own choices and going along with what others are doing can also impact howyou solve problems like SRV. On the one hand, it is important to get help and have support from others.We gain strength from our interconnections. On the other hand, youth are seeking independence and the sense that they can make their own decisions and solve their own problems (even when we know that problems like SRV are not of their own making). Figure 1, which shows a photo related to these discussions of social support, was displayed with this quote: "Having someone to go to, to talk to, if you're in a bad situation, or if you're not in a good state of mind, you can have somebody to talk to or somebody to help, and rely on." Several other photos demonstrated this theme, including a group of sticks and a pile of rocks, all images of collective strength. A number of quotes from participants illustrate their perspectives on the value of social support:

So that one's a broken stick. And that one's a whole stick. Sometimes when we have-excuse me-group support, not every stick is perfect. But if we [have] good support, we stay strong and together for the most part, but if we don't have good support, we break. Like how this stick is broken. 


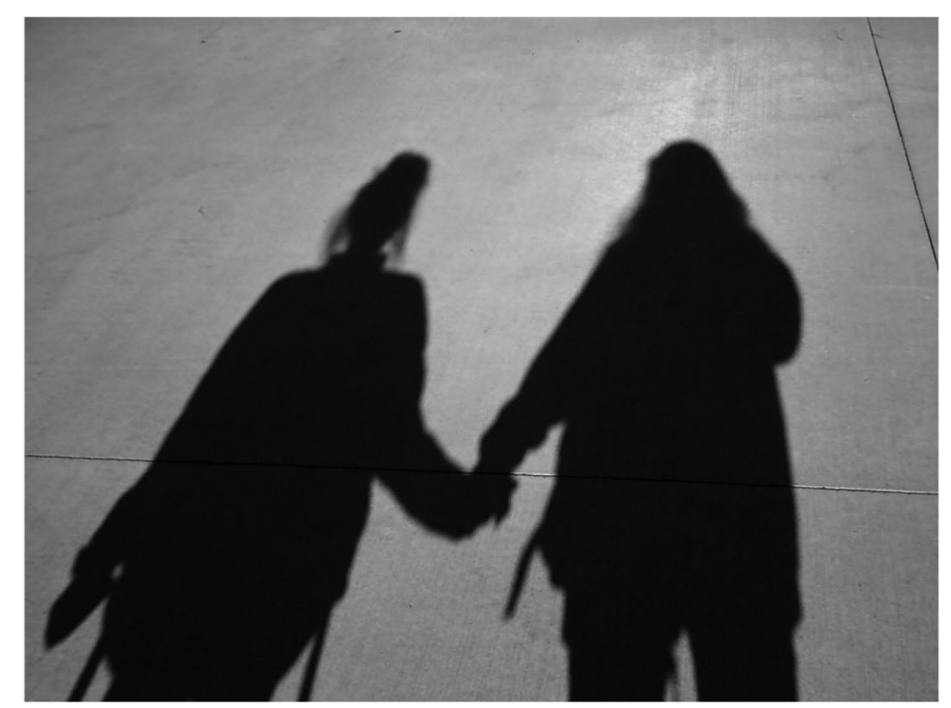

Figure 1 "Having someone to go to, to talk to, if you're in a bad situation, or if you're not in a good state of mind, you can have somebody to talk to or somebody to help..."

Your support depends on whether you're going to break or not, because it's harder to go through stuff, like a bad relationship, or like sexual violence, if you're not being supported by outside sources. It's really hard to get out of it.

All the small rocks make a bigger rock in the shadow. So they come together as one. Sometimes we need to have more than one source of support.

I feel like it's easier to make bad decisions when you have less support, than you would if you had more support.

I think it's because you can't always see everything clearly. You can't always see what's going on around you, if you're in a bad situation or not. Sometimes you can't always recognize it yourself, so you have other people around you to help support you. Sometimes they can make you realize what's going on.

The tension between support and independence can create challenges for SRV prevention since offering help (whether as a bystander to an unhealthy relationship before violence happens or afterward), while 


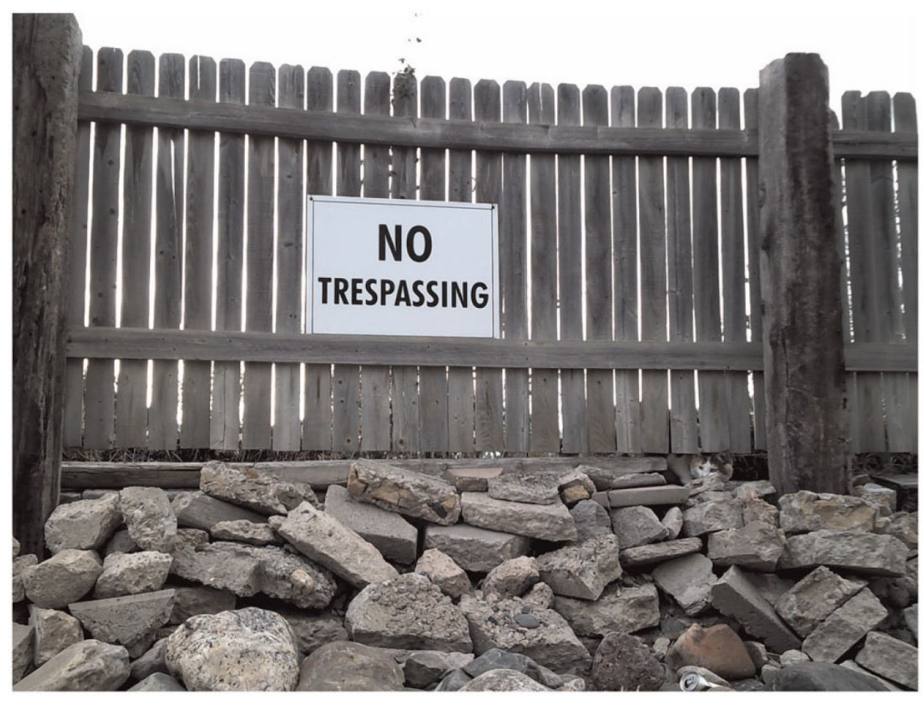

Figure 2 "Many people put up walls so that they don't get hurt." "If something happens to someone and they feel like they want to resolve and do it on their own, that's what a lot of times the problem is. I want to try to do things on my own. And I don't want to admit I need support from other people."

important to do, is not always well received. Figure 2 demonstrates this theme. It illustrates the wall that youth said they and others can put up against getting help or disclosing SRV, as do the following quotes:

Many people put up walls so that they don't get hurt.

Like usually if someone's afraid to get help in their relationship, they're afraid to tell someone because, of like either judgment or what might happen if they tell someone because they might still love the person but they don't want them to get in trouble, if that makes sense.

So sometimes you need to offer support to your friends, instead of letting them ask you for support, you need to ask them if they need support from you. Because they might be too scared. Or not sure if you're the right person to confide in. They don't want to ask.

And be a little gentle, not dreadful, about when we're helping them. And telling them it's okay to ask for help. 


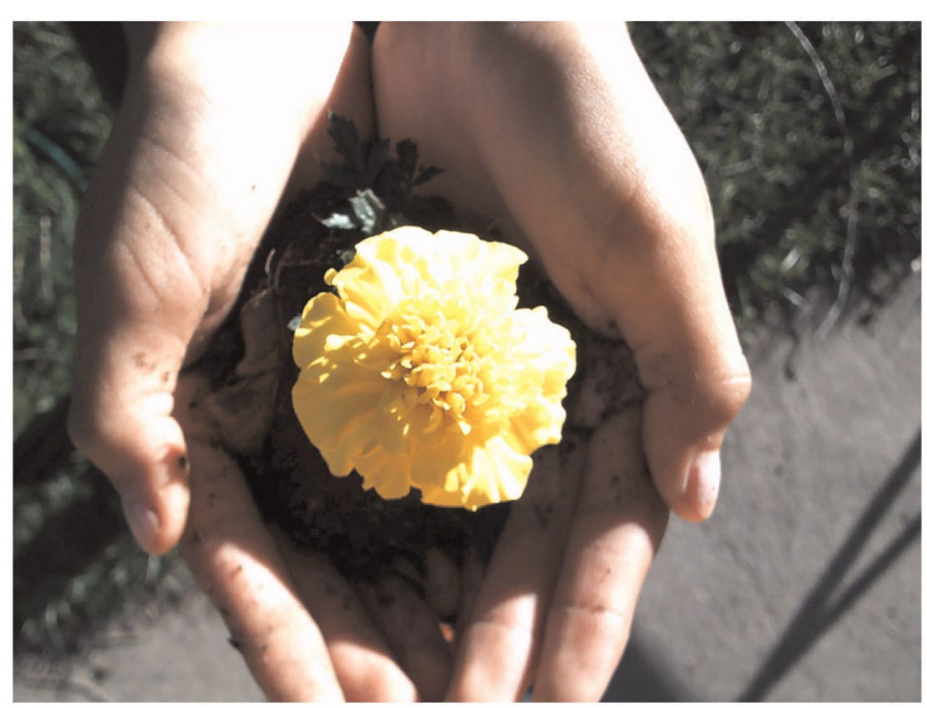

Figure 3 "You can still flourish when ... you're in really bad situations." "If you like keep trying or are persistent with the way you do things and if like, you don't give in to other people if you are persistent enough eventually you can still do ... like it's your decision to do what you're going to do."

And sometimes you push people away that are just trying to help. Sometimes you try to help people and they don't want your help. Or they don't think you can help. Or they asked for help but no one was there to give it to them.

\subsubsection{Youth are resilient actors}

The final theme was about how youth have influence and power to be prevention actors and to recover from harm they may experience. Figure 3 is a photo that sparked discussion about resilience and strengths that youth possess and fits with youth discussions of how to support survivors but also about the resilience that youth can bring to preventing complex problems like SRV: "you can still flourish when ... you're in really bad situations." "You can get back up after you have been knocked down." And as another participant noted:

If you like keep trying or are persistent with the way you do things and if like, you don't give in to other people if you are persistent enough eventually you can still do...like it's your decision to do what you're going to do. 
This theme was also echoed by youth in the reflection discussion several months after PV exhibits had taken place in multiple locations across the city. These remarks below highlight the role of youth as agents in primary and secondary prevention efforts. One participant reflected:

Adults have bias against teenagers. I think that knowing that people know that youth can achieve change and do that in the way they want to and use their voice the way they want to. I think that part is creating conversations.

Participants also talked about being active in helping others and creating change. The following quotes make this point:

I think nobody really stops it at its roots. Nobody says anything when it first starts. Like it could easily stop it when it's first started. You could have said, hey you might think about what you're doing. Sometimes it's easier to talk to people closer to your age, then that would help because they understand better.

We can be a positive bystander for speaking up for our friends when they feel comfortable because you know that they're going to support you and stick up for you and your boundaries.

If there were more positive bystanders that were willing to support someone saying something to the person who was [inaudible] or the person that's being picked on, then there wouldn't be as much people being picked on because there's more support.

So I went up to her, tried to make conversation. And ask her, "How was your day?" And what does she do for fun and stuff like that...Because once I started talking to her, and the days I wasn't talking to her I would see other people going up and asking how her day was, and most of the time it'd be my friends. 


\subsection{PV to diffuse youth prevention perspectives}

Typically, a PV project culminates in a community forum where photos, quotes, and themes are displayed for community leaders and members to view and discuss with PV participants (Wang \& Burris, 1997). The youth in the current project decided to make a "traveling exhibit." Photos and accompanying materials were mounted in a way so that the exhibit could be moved around the city and so that the display could be installed and viewed even without youth being there in person. Youth and adult facilitators felt that this was appropriate for the local community (which has many public art displays), and would allow for greater diffusion than one single exhibit. As of the writing of this paper, six PV exhibits (at a local movie theater, in art gallery spaces in the main street area, at the local area hospital, and at the police department) have occurred. There is strong community interest to have more, including in local middle and high schools. (These were scheduled had to be postponed due to the COVID-19 pandemic.)

In the last reflection discussion (Session 7), youth were asked to talk about the impact of PV on themselves and their community. Youth described how the project enabled them to learn from their peers and appreciate differences in perspectives. They also described it as an empowering experience for themselves. Further, they described how they felt it allowed their community to better hear youth voices, to see youth as actors in the community, and to start new SRV prevention conversations. This is particularly important given earlier findings from the broader study that this PV project was part of. The broader prevention evaluation began with key informant interviews about views on SRV prevention. Notably, an adult who was interviewed stated, "I would guess probably not very frequently that adults are having conversations with kids specifically about [sexual violence and dating violence]" while a youth asserted, "Like, us, as teens and young adults, we do have our voices, but we're not heard. We're put away." The comments from youth about the impact of PV suggest that it is a method that worked against the silence that existed around these issues and that is all too common in communities. It helped youth change the way they think about themselves. As one participant noted: "Knowing you can grow up and still have that support from your peers and your family and you can also give that support in [SRV] is also a responsibility." Youth learned from each other: "Saw 
the different parts of the picture, everyone saw something different." And another participant appreciated the ability to "learn about different opinions and different ways to look at things and I think I was able to learn more about how people thought and different ways that they make change." As these quotes illustrate, youth could see the community learn from them:

People can see that things are happening in our community and people are trying to help to prevent it and stop it.

To know that when people look at our photos they will think about why we took this photo and how it relates to them and their lives. That is something I strive for in my art. Knowing that I am achieving that makes me happy.

Like hearing your voice so other people can hear you maybe not through words but see how you see the world and think about things.

[PV created] a platform for awareness of SRV and all the issues of this community. PV is a safe place where you can do this anonymously and have voice.

\section{Discussion}

Research on SRV reveals not only its high prevalence among adolescents, but the need to continue to find more effective prevention strategies. The current project used PV to try to better understand how youth see SRV prevention and their role in it. Over half the enrolled youth were $\mathrm{Na}$ tive American, reflective of the demographics of the community where the project took place. From the photos youth took, and their discussions of the images, we gained a different view of SRV prevention that includes the perspectives of youth. As with previous work, youth described how SRV is present in their lives, but the current study extended previous work by focusing on SRV specifically rather than health more broadly, and focusing on prevention rather than only on impact (Bayer et al., 2014; Chonody et al., 2013; Christensen, 2019). As a result, we 
obtained a broad view of themes that youth found relevant to addressing SRV in their lives.

Youth described SRV prevention as needing to be relational, and those relationships and connections are twosided - containing both challenges and opportunities, autonomy, and interdependence. This is consistent with other PV work, in which youth described relationships like family as central to health. (Jennings \& Lowe, 2013). It is also consistent with Native American values such as the Lakota value of interconnections and relations, Mitákuye Oyás'in and Tiyóspaye (Modaff, 2019). Youth described how they value newfound freedoms and responsibilities and are engaged in setting their own boundaries around relationships that respect a desire to make their own decisions as they take on new roles in their communities. This is a common developmental theme among youth raised with individualistic societal values (Lee et al., 2010) and yet it may also make youth vulnerable to self-blame and victimblaming views of survivors if youth take on too much of a sense of agency in relation to SRV (which is the responsibility of the perpetrator) and yet agency may also be part of an important sense of empowerment (Senn et al., 2015). On the other hand, they also recognize that everyone needs support and that we only grow and succeed and recover from adversity with the connections of others, and for Native youth this includes not only peers but includes the extended family, or Tiyóspaye. The view of prevention in the current study is enriched by the diverse cultural backgrounds of the participants.

And yet, youth themselves can be hesitant to accept help for SRV and recognize that even when they offer it to others, it is not always welcome. Peer pressure can contribute to problems like SRV, but peer influence can also create positive change. These findings fit with research on the salience of peer relationships but ongoing importance of adult connections for adolescents, particularly youth connected to Native culture and traditions (Siller et al., under review). Prevention programs that build skills for healthy relationships (not just dating relationships but also friendships) may be particularly welcomed by youth. Such programs might combine the focus on friendship and conflict and emotion management often offered to younger students in social emotional learning curricula (Espelage et al., 2017) with skill building related to burgeoning intimate partnerships (Niolon et al., 2019).

Youth were also clear that, while not always recognized by adults, 
they are resilient and ready to help others. Youth described themselves as actionists across a full spectrum of SRV situations (including responding to a peer who is in an unhealthy relationship and speaking up about healthy relationships) that represent both prevention and response. These descriptions are consistent with values within Native American communities including the Lakota values of bravery, fortitude and generosity (Marshall, 2002; Modaff, 2019) and supports research on the connection between cultural values and youth resilience (Freeman et al., 2016). Indeed, youth were very clear that SRV prevention is about reaching out and taking time to help others even when it may be difficult or may involve going against social norms. These findings are also consistent with research on positive youth development (PYD) that highlights strengths and challenges deficit models of adolescence (Atkiss et al., 2011; Benson \& Scales, 2009; Bowers et al., 2010; Catalano et al., 2004; Lerner et al., 2009). To date, the PYD model, while showing widespread impact on youth well-being, has been relatively siloed from specific SRV prevention program efforts. The current study suggests that integrating these prevention approaches may be helpful for increasing youth engagement in prevention. As described in work by previous researchers using PV with youth, young people are able to describe many aspects of agency (Rose et al., 2020). The current findings fit with prior work that describes the problem of adultism (whereby adults assume youth to be inferior) (Bell, 1995) and that finds that PAR methods can overcome adultism and better support youth empowerment (Bettencourt, 2020). Connections between themes developed by youth during PV and cultural community values also support efforts to integrate positive cultural and racial identity into youth prevention (Jones \& Neblett, 2016; Kenyon et al., 2019).

The project also illustrated how PV serves as a prevention enhancing and diffusion strategy. PV started and promoted community conversations. To date, this method has more often been used to help empower survivors (an important goal) (Christensen, 2018; Frohmann, 2005). The current project showed not only how it can help us better understand how youth see SRV prevention (Edwards et al., 2016), but also how it serves as a mechanism for diffusing important prevention messages. Rogers' Diffusion of Innovation model is at the heart of many prevention strategies (Rogers, 2002). This model describes how a core group of opinion leaders who are open to a new idea can then spread the idea 
throughout their networks, ultimately saturating a community. PV could potentially be a vector for this diffusion, as youth not only discuss and learn about SRV prevention but then create community forums to share their ideas with other youth and adults. In the case of the current project, youth designed a mobile exhibit that traveled around the city where the project took place. During baseline key informant interviews for this project, youth and adults described the importance of youth voices in prevention work (Banyard et al., 2017). For example, "I think the biggest way youth could impact [sexual violence prevention] is, have a youth voice. Make sure they're getting heard." Other adults noted, "I think going to the kids is the best way to change the future of what you want to do" and "Hearing what they have to say. Having, letting them have a voice ... I mean they can have guidance and direction and give them the tools, but the story needs to be theirs." PV provides an important method for elevating those voices and stories.

\section{Implications}

The data suggest that we need to think about SRV prevention in ways that put relationships at the center. This could mean several different things. First, primary, secondary, and tertiary prevention are connected and are about helping others (after abuse as well as before). Youth talked about being actionists (something they learned from the prevention programming that was part of the larger project), but also talked about helping friends who were in problem relationships or friendships. This supports the growing consensus in the field about the important of bystander-focused programming with youth to prevent SRV (Basile et al., 2016; Coker et al., 2017; Edwards et al., 2019). The data also align with increasing calls in the literature to have youth at the center of program development and implementation (Edwards et al., 2016). Along these lines, integrating empowerment-based methodologies, such as PV, may help to reinforce prevention skills and messages being taught in other areas of the community, such as schools and youth-serving organizations, although this speculation needs empirical investigation. These data also underscore the critical need to de-silo prevention, as youth in this study noted that SRV is connected to other forms of violence such as bullying and historical trauma. 
Finally, the findings of the current study echo recent calls to move away from deficit-focused prevention and rather focus on prevention that build on youths' strengths, consistent with models of positive youth development. In the current study, youth reflected on their strengths and the strengths of other youth, even in the face of adversity, and stated that they have important perspectives that can help to prevent SRV. We urge researchers and practitioners to listen, really listen, to the voices of youth in all phases of program development, evaluation, and implementation. In the future, this should include more systematically involving youth in more aspects of data analysis as described in the model by Foster-Fishman et al. (2010).

Furthermore, where and how we engage with youth around prevention should shift to be more relational. To date, we mostly do prevention where it works for adults -in classrooms in schools where youth may or may not be surrounded by peers who are most relationally connected to them (DeGue et al., 2014). On the one hand, youth are with their peers there, but they are not necessarily with their friends in class. Efforts like Coaching Boys into Men (Miller et al., 2012) may be effective because they work with youth who are in more friendship and closely engaged peer groups (sports teams) and thus able to leverage prevention with relationships that are most important to them. Why not do prevention as part of afterschool clubs? Through religious youth groups? Our prevention to date is also still largely focused on changing individual behavior through classroom curricula and workshops. Even bystander intervention is focused on participants as individuals. What if we did more to engage and teach group skills, or to teach prevention in more naturally occurring peer groups? These innovations should be studied to see if they can significantly improve the effectiveness of prevention programming.

\section{Limitations}

There are a number of limitations to the current study. By its nature, PV takes place in small groups. While our sample of youth represented some groups in the community, it cannot be taken as representative. For example, only one youth identified as a sexual minority. A larger representation of sexual minority youth would provide a more meaningful understanding of SRV prevention among this at-risk group of youth. This 
is an important limitation, especially given recent findings that even evidence-based SRV prevention programs show diminished effects among this high risk group of teens (Coker et al., 2020) and their ideas for effective prevention is critical. Similarly, the current study was hampered by its consideration of social location variables solely as short categorical variables for race, ethnicity, sex rather than fuller explorations of more rich measures of identity. Further research is needed to examine the extent to which the themes developed by the youth in this project replicate in other samples. Further, nearly all youth in the current project had taken part in SRV prevention activities as part of the larger project. Thus, they were already primed to understand concepts like bystander intervention and the prevalence of SRV in their community. It would be interesting to conduct a PV project with youth before prevention exposure to examine how their views and lenses might be different. Also, the nature of PV is such that while we framed the project to youth as about SRV prevention, youth determined the specific photo assignments and discussion themes that were meaningful for them in relation to this frame. The research team helped to put these discussions in conversation with prevention frameworks from the field, using member checking discussions to gain assurance that themes and conclusions remained grounded in youth perspectives. There is a need for future research to continue to engage youth in discussions about their views of prevention frameworks, risk and protective factors they feel are most important for prevention and to provide their critiques of prevention strategies. Finally, future research with Native American youth may benefit from more intentional integration of cultural values into ideas for prevention of RSV given the importance to connection to culture as a prevention strategy.

\section{Conclusion}

PV is a powerful participatory action that to date has been underutilized in relation to SRV prevention. Given recent calls to empower youth to take more leadership roles in the design and implementation of prevention strategies for their peers, the method has promise for being a key piece of toolkits for prevention adaptation and implementation. The sample of youth who participated in the current study communicated new insights about SRV prevention, in particular that it needs to 
be seen as relational. Youth are well positioned to contribute to the design and dissemination of prevention strategies. They also highlighted the complexities of prevention in relational spaces where youth are trying to balance their autonomy to make their own choices, and their need for help and support.

Acknowledgments Funding for this study was provided by the U.S. Centers for Disease Control and Prevention's (CDC), National Center for Injury Prevention and Control, Grant \#U01-CE002838. The findings and conclusions in this manuscript are those of the authors and do not necessarily represent the official position of the CDC. We owe a great deal of gratitude to our school and community partners, project staff, and especially the youth. Without these individuals, this project would not have been possible. We also want to thank Dr. Alexandra Lightfoot and Linda Riggins who provided consultation and training.

Funding Centers for Disease Control and Prevention, Grant/Award Number: U01-CE002838

Conflict of interests The authors declare that there are no conflict of interests.

Peer review The peer review history for this article is available at https://publons. com/publon/10.1002/jcop.22495

\section{References}

Atkiss, K., Moyer, M., Desai, M., \& Roland, M. (2011). Positive youth development: An integration of the developmental assets theory and the socio-ecological model. American Journal of Health Education, 42(3), 171-180.

Banyard, V., Edwards, K., \& Moschella, E. (2017). Voices in prevention: Summary of key informant and focus group interviews on the Great Plains. Unpublished report.

Basile, K. C., DeGue, S., Jones, K., Freire, K., Dills, J., Smith, S. G., \& Raiford, J. L. (2016). STOP SV: A technical package to prevent sexual violence.

Bayer, A. M., Alburqueque, M., \& Participants, O. W. T. O. E. (2014). Our world through our eyes: Adolescents use photovoice to speak their mind on adolescent health, well-being, and sexuality in Lima, Peru. Health Promotion Practice, 15(5), 723-731.

Bell, J. (1995). Understanding adultism. A major obstacle to developing positive youth-adult relationships. YouthBuild USA. https://actioncivics.scoe.net/pdf/ Understanding Adultism.pdf 
Benson, P. L., \& Scales, P. C. (2009). Positive youth development and the prevention of youth aggression and violence. International Journal of Developmental Science, 3(3), 218-234.

Bettencourt, G. M. (2020). Embracing problems, processes, and contact zones: Using youth participatory action research to challenge adultism. Action Research, 18(2), 153-170.

Bowers, E. P., Li, Y., Kiely, M. K., Brittian, A., Lerner, J. V., \& Lerner, R. M. (2010). The five Cs model of positive youth development: A longitudinal analysis of confirmatory factor structure and measurement invariance. Journal of Youth and Adolescence, 39(7), 720-735.

Brush, L. D., \& Miller, E. (2019). Trouble in paradigm: “Gender transformative” programming in violence prevention. Violence Against Women, 25(14), 1635-1656.

Catalano, R. F., Berglund, M. L., Ryan, J. A., Lonczak, H. S., \& Hawkins, J. D. (2004). Positive youth development in the United States: Research findings on evaluations of positive youth development programs. The Annals of the American Academy of Political and Social Science, 591(1), 98-124.

Cattaneo, L. B., \& Chapman, A. R. (2010). The process of empowerment: a model for use in research and practice. American Psychologist, 65(7), 646-659.

Centers for Disease Control and Prevention. (2020). 2019 YRBS results. https:// www.cdc.gov/healthyyouth/data/yrbs/index.htm

Chonody, J., Ferman, B., Amitrani-Welsh, J., \& Martin, T. (2013). Violence through the eyes of youth: A photovoice exploration. Journal of Community Psychology, 41(1), 84-101.

Christensen, M. C. (2018). Using photovoice to treat trauma resulting from genderbased violence. Journal of Community Psychology, 46(6), 701-714.

Christensen, M. C. (2019). Using photovoice to address gender-based violence: A qualitative systematic review. Trauma, Violence \& Abuse, 20(4), 484-497.

Clark, N. (2012). Perseverance, determination and resistance: An Indigenous intersectional-based policy analysis of violence in the lives of Indigenous girls. In Hankivsky, O. (Ed.). An Intersectionality Based Policy Analysis Framework, 133159. Vancouver, BC: Institute for Intersectionality Research and Policy, Simon Fraser University.

Coker, A. L., Bush, H. M., Brancato, C. J., Clear, E. R., \& Recktenwald, E. A. (2019). Bystander program effectiveness to reduce violence acceptance: RCT in high schools. Journal of Family Violence, 34(3), 153-164.

Coker, A. L., Bush, H. M., Clear, E. R., Brancato, C. J., \& McCauley, H. L. (2020). Bystander program effectiveness to reduce violence and violence acceptance within sexual minority male and female high school students using a cluster RCT. Prevention Science, 21, 1-11.

Coker, A. L., Bush, H. M., Cook-Craig, P. G., DeGue, S. A., Clear, E. R., Brancato, C. J., Fisher, B. S., \& Recktenwald, E. A. (2017). RCT testing bystander effectiveness to reduce violence. American Journal of Preventive Medicine, 52(5), 566-578. https://doi.org/10.1016/j.amepre.2017.01.020 
Collins, P. H. (2017). On violence, intersectionality and transversal politics. Ethnic and Racial Studies, 40(9), 1460-1473.

Daniels, J. G. (2018). Young women's narratives of gender, sexuality and violence in Mitchell's Plain: A Photovoice project.

DeGue, S., Valle, L. A., Holt, M. K., Massetti, G. M., Matjasko, J. L., \& Tharp, A. T. (2014). A systematic review of primary prevention strategies for sexual violence perpetration. Aggression and Violent Behavior, 19(4), 346-362. https://doi. org/10.1016/j.avb.2014.05.004

Edwards, K. M. (2018). Incidence and outcomes of dating violence victimization among high school youth: The role of gender and sexual orientation. Journal of Interpersonal Violence, 33(9), 1472-1490.

Edwards, K. M., Banyard, V. L., Leader Charge, L., Koller, L., \& Fortson, B. (in press). Experiences and correlates of violence among Native American youth: A brief report. Journal of Interpersonal Violence.

Edwards, K. M., Banyard, V. L., Sessarego, S. N.,Waterman, E. A., Mitchell, K. J., \& Chang, H. (2019). Evaluation of a bystanderfocused interpersonal violence prevention program with high school students. Prevention Science, 20, 488-498.

Edwards,K.M., Banyard, V. L.,Waterman, E. A., Leyva, P.C.,Hopfauf, S., Shin, H.,\& Valente, T.W. (in press). Use of social network analysis to identify popular opinion leaders for a youth-led sexual violence prevention initiative. Violence Against Women.

Edwards, K. M., Jones, L. M., Mitchell, K. J., Hagler, M. A., \& Roberts, L. T. (2016). Building on youth's strengths: A call to include adolescents in developing, implementing, and evaluating violence prevention programs. Psychology of Violence, 6(1), 15-21.

Edwards, K. M., Siller, L., Wheeler, L., Leader Charge, L., Leader Charge, D., Bordeaux, S., Herrington, R., Hopfauf, S., \& Simon, B. (under review, 2020). Effectiveness of a sexual assault self-defense program for American Indian girls. Manuscript under review.

Espelage, D. L., Bub, K., Van Ryzin, M., \& Holt, M. K. (2017). Effects of a middle school social-emotional learning program on bullying, teen dating violence, sexual violence, and substance use in high school. National Institute of Justice, National Criminal Justice Reference Service.

Exner-Cortens, D., Eckenrode, J., \& Rothman, E. F. (2013). Longitudinal associations between teen dating violence victimization and adverse health outcomes. Pediatrics, 131(1), 71-78.

Foshee, V. A., Bauman, K. E., Ennett, S. T., Suchindran, C., Benefield, T., \& Linder, G. F. (2005). Assessing the effects of the dating violence prevention program "safe dates" using random coefficient regression modeling. Prevention Science, 6(3), 245-258.

Foster-Fishman, P. G., Law, K. M., Lichty, L. F., \& Aoun, C. (2010). Youth ReACT for social change: A method for youth participatory action research. American Journal of Community Psychology, 46(1-2), 67-83. 
Foster-Fishman, P., Nowell, B., Deacon, Z., Nievar, M. A., \& McCann, P. (2005). Using methods that matter: The impact of reflection, dialogue, and voice. American Journal of Community Psychology, 36(3-4), 275-291.

Freeman, B. J., Coll, K. M., Two Dogs, R., Iron Cloud Two Dogs, E., Iron Cloud, E., \& Robertson, P. (2016). The value of Lakota traditional healing for youth resiliency and family functioning. Journal of Aggression, Maltreatment \& Trauma, 25(5), 455-469.

Frohmann, L. (2005). The framing safety project: Photographs and narratives by battered women. Violence Against Women, 11(11), 1396-1419.

Gill, A. (2018). Survivor-centered research: Towards an intersectional gender-based violence movement. Journal of Family Violence, 33(8), 559-562.

Gutierrez, L. M. (1995). Understanding the empowerment process: Does consciousness make a difference? Social Work Research, 19(4), 229-237.

Harris, J. C., \& Linder, C. (2017). Intersections of identity and sexual violence on campus: Centering minoritized students' experiences. Stylus Publishing.

Heart, M. Y. H. B. (2003). The historical trauma response among natives and its relationship with substance abuse: A Lakota illustration. Journal of Psychoactive Drugs, 38(1-2), 5-26.

Henson, M., Sabo, S., Trujillo, A., \& Teufel-Shone, N. (2017). Identifying protective factors to promote health in American Indian and Alaska Native adolescents: A literature review. The journal of primary prevention, 13(1), 6-11.

Hodge, F. S., Pasqua, A., Marquez, C. A., \& Geishirt-Cantrell, B. (2002). Utilizing traditional storytelling to promote wellness in American Indian communities. Journal of Transcultural Nursing, 13(1), 6-11.

Irby, M. B., Hamlin, D., Rhoades, L., Freeman, N. R., Summers, P., Rhodes, S. D., \& Daniel, S. (2018). Violence as a health disparity: Adolescents' perceptions of violence depicted through photovoice. Journal of Community Psychology, 46(8), 1026-1044.

Jennings, D., \& Lowe, J. (2013). Photovoice: Giving voice to Indigenous youth. Pimatisiwin: A Journal of Aboriginal and Indigenous Community Health, 11(3), 521-537.

Jones, S. C., \& Neblett, E. W. (2016). Racial-ethnic protective factors and mechanisms in psychosocial prevention and intervention programs for Black youth. Clinical Child and Family Psychology Review, 19(2), 134-161.

Kenyon, D. B., McMahon, T. R., Simonson, A., Green-Maximo, C., Schwab, A., Huff, M., \& Sieving, R. E. (2019). My journey: Development and practice-based evidence of a culturally attuned teen pregnancy prevention program for native youth. International Journal of Environmental Research and Public Health, 16(3), 470.

Khumalo, S., Ngidi, N., Groenewald, C., Essack, Z., \& Van Heerden, A. (2018). Amazwi Ethu: Speaking back: A photovoice study of adolescent risk and resilience.

Kingston, L. (2015). The destruction of identity: Cultural genocide and indigenous peoples. Journal of Human Rights, 14(1), 63-83.

Kubicek, K., Beyer, W., Weiss, G., \& Kipke, M. D. (2012). Photovoice as a tool to adapt an HIV prevention intervention for African American young men who have sex with men. Health Promotion Practice, 13(4), 535-543. 
Lee, C.-T., Beckert, T. E., \& Goodrich, T. R. (2010). The relationship between individualistic, collectivistic, and transitional cultural value orientations and adolescents' autonomy and identity status. Journal of Youth and Adolescence, 39(8), 882-893.

Lerner, J. V., Phelps, E., Forman, Y. E., \& Bowers, E. P. (2009). Positive youth development, Handbook of Adolescent Psychology (Vol. 1).

Lightfoot, A. F., Thatcher, K., Simán, F. M., Eng, E., Merino, Y., Thomas, T., CoyneBeasley, T., \& Chapman, M. V. (2019). "What I wish my doctor knew about my life": Using photovoice with immigrant Latino adolescents to explore barriers to healthcare. Qualitative Social Work, 18(1), 60-80.

MacEntee, K. (2020). Participatory visual methods and school-based responses to HIV in rural South Africa: insights from youth, preservice and inservice teachers. Sex Education, 20(3), 316-333.

Mackworth-Young, C. R., Wringe, A., Clay, S., Chonta, M., Chiiya, C., Konayuma, K., Sievwright, K., Mbewe, M., Mwale, M., \& Stangl, A. L. (2020). Critical reflections on individual collages as a research method with young women living with HIV in Zambia. Emerging Adulthood.

Markus, S. F. (2012). Photovoice for healthy relationships: Community-based participatory HIV prevention in a rural American Indian community. American Indian and Alaska Native Mental Health Research: The Journal of the National Center, 19(1), 102-123.

Marshall, J. (2002). The Lakota way: Stories and lessons for living. Penguin.

McMahon, S., Burnham, J., \& Banyard, V. L. (2020). Bystander intervention as a prevention strategy for campus sexual violence: Perceptions of historically minoritized college students. Prevention Science, 21, 1-12.

Miller, E., Tancredi, D. J., McCauley, H. L., Decker, M. R., Virata, M. C. D., Anderson, H. A., Stetkevich, N., Brown, E. W., Moideen, F., \& Silverman, J. G. (2012). “Coaching boys into men": A cluster-randomized controlled trial of a dating violence prevention program. Journal of Adolescent Health, 51(5), 431-438.

Mitchell, C., Stuart, J., Moletsane, R., \& Nkwanyana, C. B. (2006). “Why we don't go to school on Fridays" On youth participation through photo voice in rural KwaZuluNatal. McGill Journal of Education, 41(3), 267.

Mitchell, F. M. (2018). "Water is life": Using photovoice to document American Indian perspectives on water and health. Social Work Research, 42(4), 277-289.

Modaff, D. P. (2019). Mitakuye Oyasin (we are all related): Connecting communication and culture of the Lakota. Great Plains Quarterly, 39(4), 341-362.

Moynihan, M. M., Banyard, V. L., Cares, A. C., Potter, S. J., Williams, L. M., \& Stapleton, J. G. (2015). Encouraging responses in sexual and relationship violence prevention: What program effects remain 1 year later? Journal of Interpersonal Violence, 30(1), 110-132.

Ngidi, N. D., \& Moletsane, R. (2019). Using photovoice to engage orphans to explore sexual violence in and around a township secondary school in South Africa. Sex Education, 19(4), 501-517. 
Niolon, P. H., Vivolo-Kantor, A. M., Tracy, A. J., Latzman, N. E., Little, T. D., DeGue, S., Lang, K. M., Estefan, L. F., Ghazarian, S. R., \& McIntosh, W. L. K. (2019). An RCT of dating matters: Effects on teen dating violence and relationship behaviors. American Journal of Preventive Medicine, 57(1), 13-23.

Orchowski, L. M., Edwards, K. M., Hollander, J. A., Banyard, V. L., Senn, C. Y., \& Gidycz, C. A. (2018). Integrating sexual assault resistance, bystander, and men's social norms strategies to prevent sexual violence on college campuses: A call to action. Trauma, Violence \& Abuse, 21, 811-827.

Resistance, C., \& Incite!. (2003). Critical Resistance-Incite! Statement on gender violence and the prison-industrial complex. Social Justice, 141-150.

Richie, B. E. (2015). Reimagining the movement to end gender violence: Anti-racism, prison abolition, women of color feminisms, and other radical visions of justice. University of Miami Race \& Social Justice Law and Review, 5, 257.

Rizzo, C. J., Houck, C., Barker, D., Collibee, C., Hood, E., \& Bala, K. (2020). Project STRONG: An online, parent-son intervention for the prevention of dating violence among early adolescent boys. Prevention Science, 1-12.

Rogers, E. M. (2002). Diffusion of preventive innovations. Addictive Behaviors, 27(6), 989-993.

Rose, T., Hope, M. O., Thurman, D., Forrester, P., \& Rose, R. (2020). Nonorganizational religious involvement and psychosocial well-being among African American and Caribbean black youth. Journal of Black Psychology, 46(5), 388-422.

Rutman, S., Park, A., Castor, M., Taualii, M., \& Forquera, R. (2008). Urban American Indian and Alaska native youth: Youth risk behavior survey 1997-2003. Maternal and Child Health Journal, 12(1), 76-81. https://doi.org/10.1007/ s10995-008-0351-3

Senn, C. Y., Eliasziw, M., Barata, P. C., Thurston, W. E., Newby-Clark, I. R., Radtke, H. L., \& Hobden, K. L. (2015). Efficacy of a sexual assault resistance program for university women. New England Journal of Medicine, 372(24), 2326-2335.

Sidibe, T., Turner, K., Sparks, A., Woods-Jaeger, B., \& Lightfoot, A. (2018). "You Still Got to See Where She's Coming From": Using photovoice to understand african american female adolescents' perspectives on sexual risk. The Journal of Early Adolescence, 38(1), 12-27.

Siller, L., Edwards, K. M., Leader Charge, L., Bordeaux, S., Leader Charge, D., \& Herrington, R. (under review). "I learned that I am worth defending": A qualitative evaluation of the No Means No IMpower Program on an Indian reservation.

Sprague Martinez, L., Richards-Schuster, K., Teixeira, S., \& Augsberger, A. (2018). The power of prevention and youth voice: A strategy for social work to ensure youths' healthy development. Social Work, 63(2), 135-143.

Strack, R. W., Magill, C., \& McDonagh, K. (2004). Engaging youth through photovoice. Health Promotion Practice, 5(1), 49-58.

Suprapto, N., Sunarti, T., Suliyanah, D. W., Hidayaatullaah, H. N., Adam, A. S., \& Mubarok, H. (2020). A systematic review of photovoice as participatory action research strategies. International Journal of Evaluation \& Research and Education, 9(3), 675-683. 
Testa, M., Hoffman, J. H., Livingston, J. A., \& Turrisi, R. (2010). Preventing college women's sexual victimization through parent based intervention: A randomized controlled trial. Prevention Science, 11(3), 308-318.

Tilbury, C., Struthers, K., \& Parmenter, N. (2019). Young people as agents of change in preventing violence against women. Australia's National Research Organisation for Women's Safety Limited (ANROWS). https://apo.org.au/sites/default/files/ resource-files/2019-05/apo-nid238121_1.pdf

Vagi, K. J., Rothman, E. F., Latzman, N. E., Tharp, A. T., Hall, D. M., \& Breiding, M. J. (2013). Beyond correlates: A review of risk and protective factors for adolescent dating violence perpetration. Journal of Youth and Adolescence, 42(4), 633-649.

Vaismoradi, M., Turunen, H., \& Bondas, T. (2013). Content analysis and thematic analysis: Implications for conducting a qualitative descriptive study. Nursing \& Health Sciences, 15(3), 398-405.

Wang, C., \& Burris, M. A. (1997). Photovoice: Concept, methodology, and use for participatory needs assessment. Health Education \& Behavior, 24(3), 369-387.

Wang, C. C. (1999). Photovoice: A participatory action research strategy applied to women's health. Journal of Women's Health, 8(2), 185-192.

Wang, C. C., Yi, W. K., Tao, Z. W., \& Carovano, K. (1998). Photovoice as a participatory health promotion strategy. Health Promotion International, 13(1), 75-86.

Waterman, E. A., Edwards, K. M., Banyard, V. L., \& Chang, H. Age and sexual orientation moderated the effects of a bystander-focused interpersonal violence prevention program for high school students. Manuscript under review.

Waterman, E. A., Hutchison, C., Edwards, K. M., Hopfauf, S. L., Simon, B. R., \& Banyard, V. L. (under review, Journal of Prevention and Health Promotion). A process evaluation of a youth-led sexual violence prevention initiative. Manuscript submitted for publication.

Woods-Jaeger, B. A., Sparks, A., Turner, K., Griffith, T., Jackson, M., \& Lightfoot, A. F. (2013). Exploring the social and community context of African American adolescents' HIV vulnerability. Qualitative Health Research, 23(11), 1541-1550.

Yuan, N. P., Gaines, T. L., Jones, L. M., Rodriguez, L. M., Hamilton, N., \& Kinnish, K. (2016). Bridging the gap between research and practice by strengthening academic-community partnerships for violence research. Psychology of Violence, 6(1), 27-33. 